\title{
ASPECTOS DA RESILIÊNCIA DO SISTEMA TRIBUTÁRIO BRASILEIRO
}

\section{Natália Brasil Dib ${ }^{1}$}

\author{
Sérgio Fernando Ferreira de Lima ${ }^{2}$
}

\begin{abstract}
Resumo
Com a superação do reducionismo epistemológico, característico da racionalidade moderna (caracterizada pelo paradigma newton-cartesiano), e a emergência da ciência da complexidade - particularmente através da teoria do caos, da segunda lei da termodinâmica e dos sistemas adaptativos complexos - surgiram novas perspectivas para as ciências sociais, não mais tão segregadas das ditas ciências naturais. Essa possibilidade levou ao estudo, mesmo que tardio, dos sistemas sociais a partir da teoria da complexidade. Partindo desse pressuposto, este trabalho analisa a resiliência - uma das características dos sistemas adaptativos complexos - do Sistema Tributário Brasileiro. Identificou-se na literatura as principais definições de resiliência e aplicou-se esses conceitos no Sistema Tributário Brasileiro. Um sistema que foi estruturado não apenas pela Constituição de 1988, mas pela Emenda Constitucional 1/1965, sob a égide da Constituição de 1946. Com isso, identificou-se algumas das principais características da resiliência do sistema tributário nacional, uma vez que tais fatores corroboram com a análise do que precisa ser alterado para que o sistema mude de fase, ou seja, para que seja viável, por exemplo, a tão discutida reforma tributária.
\end{abstract}

Palavras-chave: Resiliência, Complexidade, Sistema Tributário, Tributação, Sistemas Adaptativos Complexos.

\section{INTRODUÇÃO}

Ao pensarmos no sistema legal de qualquer Estado, num primeiro momento, tendemos a associar referido sistema com o conjunto de normas jurídicas, decorrentes das necessidades sociais de regulação, controle, organização e segurança das relações sociais daquele Estado. Se analisarmos a história de alguns sistemas legais veremos mudanças mais ou menos drásticas de determinadas partes do sistema, muitas vezes, em decorrências das pressões sociais ou econômicas, resultando, não raro, em completa reestruturação do sistema jurídico, como ocorre em uma revolução e/ou promulgação de uma nova Constituição que mude o paradigma antes adotado, tal como ocorreu no Brasil em 1988. Seja através de mudanças planejadas longamente ou em atos de urgência

\footnotetext{
${ }^{1}$ Mestre em Direito Econômico e Socioambiental pela PUCPR. Pesquisadora do Instituto Brasileiro de Processo e Procedimento Tributário. Doutoranda pela PUCPR. Membro do Grupo de Pesquisas Tributação, Complexidade e DesenvolvimentoSustentável - CNPq/PPGD/PUCPR. E-mail: nataliabrasildib@yahoo.com.br

${ }^{2}$ Mestrando pela PUCPR. Membro do Grupo de Pesquisas Tributação, Complexidade e Desenvolvimento Sustentável CNPq/PPGD/PUCPR. E-mail: sergioffernando@gmail.com
} 
socioeconômica o Direito, enquanto conjunto de normas reguladoras da sociedade, está sempre se adaptando e procurando modular os sistemas econômicos e sociais que lhe deram origem.

Essas características que delineiam cenários de mudanças e instabilidades não são típicas apenas de sistemas sociais e econômicos, mas também, e principalmente, de sistemas naturais e artificiais, que são classificados como Sistemas Adaptativos Complexos. Sistemas estudados pela grande área de estudo denominada Ciências da Complexidade, que ganhou enorme evidência e espaço nas últimas décadas, especialmente por meio dos trabalhos de Ilya Prigogine em termodinâmica (PRIGOGINE, STENGERS, 1990), do Instituto Santa Fé em Economia (onde emergiu novo campo de estudos econômicos chamado Complexty Economics) e demais trabalhos desenvolvidos por biólogos, químicos, economistas, psicólogos, que influenciaram a atualmente denominada ciência da complexidade. Posteriormente, da ecologia às ciências sociais o estudo da complexidade vem sendo usado como nova forma de abordar os diferentes aspectos de cada uma dessas áreas científicas. O Direito não foi exceção. Identificado como sistema complexo por diversos autores (RUHL, 2008; BENROCKER, 2006; FOLLONI 2013, 2016.), apresenta várias características dos denominados sistemas adaptativos complexos, possibilitando a análise que se faz neste artigo.

A partir do marco teórico delimitado, considerando o Direito - enquanto sistema de normas jurídicas destinado a regulamentar as relações sociais - um sistema complexo -, este estudo pretende abordar as características da resiliência do sistema das normas tributárias, apontando algumas delas que demonstram o grau de resistência do sistema para modificações significativas.

A relevância no estudo está na constante discussão sobre a necessária reforma tributária no Brasil. A despeito de qualquer juízo de valor que se repute necessário para a decisão acerca da modificação do modelo tributário, fato é que desde de meados da década de 1960, quando surge o modelo de tributação tal qual é hoje, ratificado e ampliado pela Constituição de 1988, foram propostas pelo menos 03 PECs (propostas de emendas constitucionais) relevantes sobre o tema e que apresentam pontos em comum (JUNQUEIRA, 2015). Todas elas infrutíferas. O que demonstra que a discussão acerca da resiliência do Sistema Tributário Nacional mostra-se útil para o cenário nacional.

Pretender a modificação do referido sistema implica, a nosso ver, na compreensão das características do sistema que precisam ser atingidas para que possa se pensar numa proposta viável e que alcance os objetivos pretendidos. Lembrando, sempre, que o conjunto de normas que regem as relações sociais pretendem a interferência em fenômenos complexos, de modo que a dinamicidade do sistema acaba por se configurar ponto necessário para o alcance dos objetivos sociais (RUHL, 1996, 2008, 2011).

Sendo assim, o presente trabalho será regido por três eixos condutores: o primeiro consiste na conceituação dos sistemas adaptativos complexos e da resiliência; o segundo consiste na identificação das 
características principais do Sistema Tributário Nacional, principalmente a partir da publicação do Código Tributário Nacional, em 1966, e da Constituição de 1988; e a terceira na determinação de hipóteses - certamente não exaustivas - das características do sistema tributário nacional que o faz resiliente às tentativas de modificação.

\section{COMPLEXIDADE E RESILIÊNCIA}

Como parte da tradição científica newton-cartesiana, a forma preponderante de empreender o estudo de qualquer objeto ou tema, se dava por meio da cuidadosa análise de seus componentes, de suas partes de forma dissociada (PRIGOGINE, STENGERS, 1984, p.xi). Acreditava-se que através do detalhado conhecimento das partes poder-se-ia conhecer (e prever) o comportamento do sistema formado por todas os elementos analisados segundo a ideia laplaciana de linearidade (MITCHELL, 2009, p. 19). Entretanto, no final da década de 70, nas ciências exatas, começaram a surgir áreas de estudo nas quais constatou-se que o conhecimento das partes não pressupunha a explicação e previsibilidade do funcionamento do todo: a teoria do caos, os sistemas termodinâmicos longe do equilíbrio começaram a formar grandes campos de estudo (BYRNE, 1988, p. 18). Já em meados da década de 80 encontramos diversas áreas nas quais o comportamento e as propriedades dos sistemas não se adequavam ao paradigma reducionista, emergindo deste contexto as Ciências da Complexidade.

Complexidade que não se confunde com complicação. O funcionamento de um relógio pode ser complicado, mas não é complexo. Já o funcionamento do sistema imunológico é complexo, não apenas complicado. Um sistema complexo exibe várias características que o distingue de outros sistemas, dentre as quais destacam-se: 1) o comportamento coletivo complexo - auto-organização: uma rede de elementos individuais (células, pessoas, instituições, leis, computadores, etc.), com ausência de um líder ou controle coletivo (cada célula, pessoa, instituição, persegue objetivos próprios de acordo com parâmetros individuais) organiza-se. 2) Das ações individuais do vasto número de componentes do sistema resultam padrões emergentes não previsíveis individualmente, característicos de sistemas complexos (ordem emergindo do caos); 3) processamento de informações internas e externas, pois todos esses sistemas produzem e processam informações constantemente; 4) adaptabilidade: são sistemas que se adaptam, ou seja, mudam seu comportamento aprendendo através do processamento de informação ou através de processos evolutivos (MITCHELL, 2009, p.13).

Ademais, ao contrário do que a lógica reducionista levou a crer, os sistemas complexos não são a exceção no mundo real. O paradigma científico reducionista, predominante desde Galileu e Newton, afirmava que toda a realidade, desde um casal apaixonado até os planetas e estrelas não são mais que agregados de elementos mais simples (partículas) em movimento. Assim a explicação para estruturas com um alto grau de complexidade estaria sempre nos seus elementos constituintes, mais simples. Sociedades poderiam ser explicadas através de leis sobre o comportamento dos indivíduos, que por sua vez poderiam ser explicados pela compreensão do funcionamento 
dos órgãos que compõem cada indivíduo, que poderiam ser explicados através das leis que regem o mecanismo celular, que poderia ser demostrado através da bioquímica, que tem sua gênese na química, que pode ser explicada pela física e, finalmente, pela física de partículas. (KAUFFMAN, 2010, p.27).

Esta visão permeou quase todos os campos científicos até bem pouco tempo, tendo sido amplamente aplicada ao Direito através do positivismo jurídico, sendo facilmente identificável na ênfase dada ao estudo "puro da norma jurídica", como forma de fazer a verdadeira "ciência jurídica". Assim, Kelsen sublinha esta teoria: "caracteriza a si mesma como uma teoria 'pura' da lei porque tem por objetivo a cognição focada apenas na lei[...] Ou seja, a Pura Teoria procura livrar a ciência jurídica de todos os seus elementos estranhos 3" (KELSEN, 1992, p.7).

A maioria dos fenômenos da realidade apresentam-se como sistemas adaptativos complexos: ecossistemas, economia, sistemas biológicos, os sistemas sociais, a internet, etc. Basta notar que se as ciências da complexidade eram novidade no final do século XX, muitas das mais proeminentes áreas científicas atuais não poderiam existir sem os métodos e simulações das quais dependem e que surgiram com a Complexidade; como a biologia de sistemas, a climatologia, a neuropsicologia, a astrofísica, a geodinâmica, a engenharia de tráfego. Outras áreas têm usado um volume cada vez maior de aporte de ferramental e teorias das ciências da complexidade desde a antropologia ao estudo de guerras (HOOKER, 2011, p.5).

Os sistemas adaptativos complexos, por sua vez, de acordo com Mitchell (2009, p. 13) e Holland (2014, p.37), são sistemas compostos de multiplicidade de elementos (agentes) que se adaptam, por meio do aprendizado e da experiência, através de suas interações com os demais agentes, e mantêm a estrutura e a funcionalidade básica do sistema através de uma propriedade chamada resiliência (RUHL, 2008, p. 895).

A resiliência, a partir dessa perspectiva, foi primeiramente estudada pela ecologia. A partir do seu estudo seminal, Holling publica em 1973 seu trabalho intitulado: Resilience and Stability of Ecological System ${ }^{4 "}$ no qual descreve vários estados possíveis de equilíbrio, nem sempre previsíveis, em um ecossistema, contrariamente ao estado único e previsível que se acreditava existir. A percepção de que os sistemas conhecidos deveriam ter pontos previsíveis de equilíbrio era comum nas diversas áreas científicas, como a economia, em que a teoria tradicional conta com modelos de equilíbrio previsíveis (BEINHOCKER, 2006, p. 32).

No novo modelo proposto por HOLLING (1973) a quantidade de perturbações que o sistema poderia absorver antes de mudar de estado de equilíbrio foi chamada de resiliência. Essa é praticamente a definição atual que é: a capacidade de um sistema de absorver perturbações e ainda manter sua estrutura e função básica (HUMBY, 2014, p.90). De forma mais precisa, WALKER et al. (2004, p. 01) definem resiliência como a

\footnotetext{
${ }^{3}$ Nossa tradução: "It characterizes itself as a 'pure' theory of law because it aims at cognition focused on the law alone [...]That is, the Pure Theory aims to free legal science of all foreign elements."

4 "Resiliência e estabilidade nos sistemas ecológicos".
} 
capacidade de um sistema em absorver perturbações e reorganizar-se enquanto sofre mudanças, de forma a manter, essencialmente, a mesma função, estrutura, identidade e respostas.

Sistemas Adaptativos Complexos: ecossistemas, economias e sociedades, sistemas complexos baseados em agentes autônomos: pessoas, instituições, empresas, que perseguem seus objetivos individuais e interagem entre si e com seu ambiente. Nesse contexto, qual a importância da resiliência? O estudo da resiliência toca questões fundamentais que dizem respeito à estabilidade desses sistemas: Por quanto tempo um sistema permanecerá em determinado estado? Quanto das suas características fundamentais mudarão com o tempo? Quão sensíveis são a perturbações? Se perturbados, retornarão ao seu estado original, se sim, por quê? A partir de qual conjunto de estados? Quão rápido? (GRIMM, CALABRESE, 2011, p. 06).

Mas qual a melhor e mais precisa definição de resiliência? A primeira noção que surge com a palavra é, em certa medida, atribuída a uma forma de estabilidade. As várias noções de estabilidade em ecologia já foram catalogadas e montam o número de 163 definições, de 70 possíveis tipos de estabilidade (GRIMM, WISSEL, 1997, p. 324). Para este trabalho tomaremos as definições de Holling desde seu trabalho seminal em 1973 até publicações mais recentes, como também as considerações de outros autores, a fim de encontrar uma definição que possa ser melhor utilizada no estudo aqui proposto.

Podemos distinguir dois tipos de resiliência, a resiliência mecânica ${ }^{5}$ e a resiliência ecológica. A resiliência mecânica pode ser usada como sinônimo de elasticidade (GRIMM, CALABRESE, 2011, p. 6) pois ela se configura como a proporção e a velocidade com que um sistema retoma ao estado original após sofrer perturbações (HOLLING, GUNDERSON, 2002, p. 27). Pode-se sublinhar, como faz RUHL (2011, p. 1376), que a resiliência mecânica enfatiza aspectos estratégicos como a eficiência, o controle de qualidade, a constância, como formas de reaver o estado perdido de equilíbrio. Entretanto, a resiliência mecânica possui limitações, pois não permite o estudo do sistema completo e como sua organização interna e mecanismos promovem a permanência, a despeito das perturbações sofridas (GRIMM, CALABRESE, 2011, p. 07).

Em busca de definição mais adequada Holling propõe a ideia de resiliência ecológica, que seria caracterizada mais qualitativa que quantitativamente, pois neste caso, a "resiliência determinaria a persistência das relações dentro de um sistema e é uma medida da habilidade destes sistemas em absorver mudanças de variáveis de estado, variáveis de direção e parâmetros, e ainda assim se manter." (HOLLING, 1973, p. 17). Quando RUHL trata da resiliência ecológica, aponta que ela seria a "magnitude da perturbação que um sistema poderia absorver sem ter sua estrutura e comportamento fundamental redefinidos" (RUHL, 2011, p. 1376).

O exemplo mais claro de distinção entre as duas formas de resiliência é o citado por RUHL (2011, p.

\footnotetext{
${ }^{5}$ Tradução escolhida para o termo Engineering Resilience, que acreditamos, expressa melhor as características deste tipo de resiliência.
} 
1377), quando descreve dois vasos, um fundo e estreito e o outro amplo e raso. Ambos com uma esfera no fundo. A esfera parada no fundo dos vasos encontra-se em equilíbrio. Se os vasos são balançados com diferentes intensidades teremos respostas diversas para cada caso. A esfera no vaso longo e estreito tem pouca latitude (espaço) para mover-se internamente e rapidamente retornará ao repouso no fundo do vaso, sendo um ótimo exemplo do comportamento da resiliência mecânica. A esfera no vaso amplo e mais plano, por sua vez, poderá se afastar muito mais de seu ponto de repouso até atingir as bordas (limites) do vaso e pode até mesmo repousar em pontos diferentes do inicial (vários possíveis estados de equilíbrio), exemplificando a resiliência ecológica.

Essa distinção foi fundamental para o estudo de sistemas ecológicos, pois a imensa maioria das políticas de preservação do meio ambiente, em todos os países, são construídas pensando em um ponto de equilíbrio dos ecossistemas, previsível e razoavelmente não mutável. Entretanto, ao aplicar a ideia de resiliência mecânica a criação de leis e diretrizes que devem reger um sistema de resiliência ecológica (como os ecossistemas) acaba-se por se obter o resultado inverso, diminuindo-se a resiliência do sistema e aumentando a possibilidade de mudanças drásticas e não desejadas (extinções de espécies, desertificação de áreas, etc.). E, em alguma medida, podemos afirmar que as normas que regulam o sistema tributário foram pensadas de modo semelhante. Espera-se pela consequência precípua da norma, muitas das vezes desconsiderando o contexto social. Pense-se, por exemplo, na tributação sobre o consumo tão criticada pela doutrina (LODI RIBEIRO, 2015, p.10-11, JUNQUEIRA, 2015, p. 95). Certamente, a finalidade desse sistema de normas não era o aumento das desigualdades sociais. Contudo, os estudos mais recentes demonstram que referida tributação mostra-se extremamente desigual. A previsibilidade pretendida pela norma, nesse sentido, não se opera.

Considerando as definições já vistas, a resiliência procurará manter as funções, estruturas e identidade fundamentais do sistema adaptativo complexo à medida que as perturbações o acometem. Entretanto, algumas perturbações podem levar o sistema a exceder seu limite de resiliência, empurrando todo o sistema a buscar novo estado de equilíbrio - geralmente por meio de simplificações estruturais e mudanças, que podem ser traduzidas em eventos de extrema mudança, no qual o resultado não pode ser antecipado (CASTI, 2012, p.95).

Quando aplicamos a teoria da resiliência aos sistemas econômicos e sociais, geralmente veremos crises financeiras, revoltas sociais, das mudanças nas estruturas institucionais de determinada sociedade, ou estruturas, padrões e instituições difíceis de serem alteradas. A economia foi uma das primeiras áreas, fora do campo das ciências exatas e biológicas, a aplicar o conceito de resiliência para mensurar a capacidade de recuperação das economias (MAYNTZ, 2016, p. 64), assim também, as ciências sociais seguindo o mesmo passo, retiraram questionamentos de fundamental importância da teoria da resiliência: que fatores provocam (ou previnem) a instabilidade e a mudança em uma instituição, um Estado ou uma sociedade? Que regras sociais previnem ou aceleram os processos disruptivos? (MAURER, 2016, p.2). 
O Direito não ficou alheio nem ao impacto das Ciências da Complexidade nem às ideais trazidas pela resiliência. Até 2014, cerca de 74 papersforam publicados em revistas internacionais de Direito abordando o tema (HUMBY, 2014, p.88). Em seu trabalho sobre resiliência e Direito Ambiental, Ruhl (2011, p. 1379) sublinha que o sistema legal, como qualquer outro sistema, pode ser definido pela sua estrutura e processos. Configurações diferentes dessa estrutura e processos produzirão diferentes respostas a perturbações e mudanças internas e externas. A forma como é estruturado o sistema jurídico também afeta como ele suportará perturbações de diferentes qualidades e magnitudes ao longo do tempo. Talvez, seja interessante que parcelas do sistema jurídico possam ser estruturadas de forma a apresentar tipos diferentes de resiliência (mecânica ou ecológica) de acordo com sua finalidade (RUHL, 2011). Além disso, as normas legais, por excelência, harmonizam interações entre pessoas, e o Direito, dessa forma, provêm a base para a manutenção da persistência das relações sociais e econômicas entre as pessoas. (HOLLING, 2012; BEINHOCKER, 2006; QUEIROZ, 2003, p. 80).

O Sistema jurídico pode ser compreendido como um sistema adaptativo complexo (RUHL,2008; BYRNE, 1998 FOLLONI, 2013) que regula (e portanto interage) com outros sistemas adaptativos complexos (economia e sociedade). E na mesma medida que se procura os fatores essenciais (Golden Factors) de manutenção da resiliência em um sistema social (MAURER, 2016, p. 84) poderíamos procurá-los no Sistema Jurídico? Sendo o Sistema Jurídico o principal regulador das relações sociais, como deverá se estruturar para promover a resiliência dos sistemas por ele regulados? Esta promoção de resiliência é sempre desejável e possível? É sempre desejável e possível a manutenção da maior resiliência possível no próprio Sistema Jurídico? Para o escopo do presente artigo, elegemos o Sistema Tributário Nacional como ponto focal para nossos primeiros questionamentos sobre resiliência e Direito.

\section{O SISTEMA TRIBUTÁRIO BRASILEIRO E A RESILIÊNCIA}

Tal como já defendemos em outro trabalho (DIB, 2015), o fenômeno jurídico é complexo (RUHL, 1996, p. 856, FOLLONI, 2013, 2016; TEUBNER, 1993; SCHOUERI, 2005, p.8; CALIENDO, 2009, p.7; ÁVILA, 2012, p. 57). Com referida afirmativa quer se dizer que o fenômeno regulado pelas leis é um sistema complexo, compreendendo todas as características anteriormente mencionadas. Nesse sentido, Ruhl (2008, p. 897) estuda o direito como um sistema adaptativo complexo, considerando as leis como fenômenos emergentes a partir da interação social ${ }^{6}$. Explica o autor que tal perspectiva é necessária pois:

Primeiro, o sistema legal como uma fonte de regras para a regulação de outros sistemas sociais, deve levar em conta a forma como estes sistemas operam. Se alguém deseja regular

\footnotetext{
${ }^{6}$ Esclarece-se que não se está a conceber a teoria dos sistemas adaptativos complexos como a única forma de estudo do direito ou mesmo da complexidade. A intenção é demonstrar como o fenômeno social na sua perspectiva complexa exige a transformação na dogmática jurídica.
} 
um complexo adaptativo sistema social, deve-se pensar como um sistema complexo adaptativo social. Em segundo lugar, o direito, como uma coleção de regras e regulamentos, é o produto do sistema legal, dum conjunto de pessoas e instituições. Lei, nesse sentido, é simplesmente uma propriedade emergente do sistema legal da mesma forma que os preços são uma propriedade emergente de mercados.

O direito, assim como seu estudo, deve possuir flexibilidade, dinamicidade, pois regula fenômenos complexos que estão em constate interação e modificação. A regra jurídica deve ter a "capacidade de adaptação às mais diversas situações (RUHL, 2008, p. 897).”

Partindo, então, do pressuposto de que o fenômeno jurídico é complexo e que, por consequência, o conjunto de normas que o regula também é, já que emerge das relações sociais, é que se pretende a análise, neste trabalho, da resiliência do Sistema Tributário Brasileiro, aqui limitado à questão normativa.

O Estado brasileiro é tipicamente um Estado Fiscal - ou seja, Estado com deveres de cumprimento de seus objetivos constitucionais financiados pela tributação (NABAIS, 1998, p. 192-194, DIB, 2015, p. 41). Determina a Constituição Federal que a sociedade brasileira pauta-se sobre a livre iniciativa (GRAU, 2008, pp. 6989/252/347), de modo que ao cidadão é dado o direito ao livre desenvolvimento das atividades econômicas e ao Estado essa atividade se dá de forma residual. Desse modo, o sustento da máquina pública se dá por meio da participação compulsória na atividade econômica, ou seja, por meio da tributação. Trata-se do preço da liberdade (TORRES, 2002, p. 8-9). Sendo assim, dentre outras, essa pode ser considerada uma das principais funções do tributo, qual seja, o financiamento estatal para que possa cumprir os objetivos fundamentais delineados constitucionalmente. Essa perspectiva traz, necessariamente, novos rumos ao direito tributário (do poder à função) e, via de consequências, às normas que o regulam. O Estado não está mais investido, apenas, no poder de tributar, mas, primordialmente, na função de tributar, sempre com vistas ao cumprimento dos objetivos fundamentais da República (art. $3^{\circ}$ da CR/88) (BOBBIO, 2007, p.17. BARROSO, 2007, p.21. MIRANDA, 2002, pp.230-231. CALIENDO, 2009, p.142).

Dessa forma, pode-se afirmar que a finalidade do sistema tributário é a equalização entre a interferência no patrimônio individual e a garantia do bem jurídico coletivo, com vistas à arrecadação tributária, pode-se afirmar, é um dos atratores do sistema (DIB, 2015, p. 69)

Pois bem, partindo desse pressuposto, o conjunto de normas que regulamenta a tributação passa a ter importante função na determinação do alcance do tributo. Isso porque, há evidente interação entre a necessidade de financiamento da máquina pública para o alcance do interesse público primário e a preservação do direito fundamental à propriedade privada, pertencente a cada cidadão. Mas como se opera a alteração desse sistema de normas de modo a atender aos anseios sociais que são dinâmicos e interativos?

O Sistema Tributário Nacional, como o conjunto de normas tendente à regular a relação jurídicotributária, pode-se afirmar, emerge de forma estruturada apenas em 1966 com a edição do Código Tributário 
Nacional e com a emenda constitucional n. 18/1965 (no auge do regime militar). Antes disso, como relatam alguns estudiosos (FOLLONI. 2013, p. 46 e ss.) - bem como um dos idealizadores do Código Tributário Nacional, Rubens Gomes de Souza (1964) - a tributação no Brasil vinha regulada por uma série de normas esparsas e desorganizadas, fortemente imiscuídas com o direito financeiro e administrativo, de modo a causar grande insegurança jurídica (o que se pode afirmar não foi solucionado pelo sistema em si).

Anos depois, referido sistema foi incorporado à Constituição de 1988, que ampliou a estrutura da tributação no Brasil e dedicou um capítulo próprio ao Sistema Tributário Nacional, fazendo constar de forma detalhada toda a estrutura da instituição de tributos, tornando o texto constitucional a fonte normativa para a instituição de qualquer tributo no país.

Contudo, 50 anos após a edição do CTN e quase 30 anos após a promulgação da Constituição, o Sistema Tributário Nacional continua sendo um problema. A pretendida segurança jurídica (MARINS, 2016; ÁVILA, 2012) não se operou, fazendo com que desde a criação do Sistema Normativo Tributário atual, sua reforma seja pleiteada. "Hoje, após quase meio século de trabalho, persistem os mesmo desentendimentos e perplexidades. Pior: a Receita Federal do Brasil publica uma média de cem instruções normativas por ano, uma a cada dois ou três dias úteis!" (FOLLONI, 2013, p. 47). Além disso, a tributação, da forma como prevista, favorece a regressividade - e por consequência a desigualdade social (JUNQUEIRA, 2015 LODI RIBEIRO, 2015) - gera altos custos de Compliance para as empresas (o maior do mundo - PWC, 2016), onera grandemente o consumo em detrimento da renda e da herança (LODI RIBEIRO, 2015), indo, em princípio, de encontro aos objetivos delineados constitucionalmente.

Nesse sentido, a reforma do sistema tributário é pauta recorrente na academia, na política, na economia, exigindo a alteração da sua estrutura como necessário para o atingimento dos objetivos fundamentais da nação. A despeito da análise valorativa acerca da necessidade da reforma tributária e da eficiência da tributação (que não encontra espaço neste trabalho) assume-se que referida reforma é pleito constante no Estado Brasileiro, de modo que a sua viabilidade se torna ponto importante de estudo.

Tal como expõe Murilo de Oliveira Junqueira, desde a promulgação da Constituição de 1988 já foram propostas três emendas, considerando apenas as de iniciativa do poder Executivo, à Constituição para reforma do sistema tributário (PEC 175/1995; PEC 31/2007 e PEC 233/2008). Todas elas fracassadas. Isso sem considerar as tantas outras propostas que sequer ganharam relevo. Do ponto de vista da complexidade do sistema, por qual razão referidas reformas não se operaram? Quais as características do sistema normativo tributário que dificultam a sua alteração e fazem com que o sistema resista?

É nesse cenário que se insere a análise aqui pretendida. Tomando-se o Direito e o Sistema Tributário Nacional, que regula a tributação no país, como um sistema adaptativo complexo, insere-se a questão: quais as 
características da resiliência desse sistema que dificulta a sua modificação?

\section{CARACTERÍSTICAS DO SISTEMA NORMATIVO TRIBUTÁRIO}

Como exposto anteriormente os sistemas adaptativos complexos caracterizam-se pela resiliência, ou seja, pela capacidade de adaptarem-se às perturbações mantendo suas características e sua funcionalidade, sem que haja mudança de fase do sistema.

Nesse sentido, como explica André Folloni (2016, pp 41-42.), os sistemas complexos "sobrevivem à morte de alguns de seus elementos, e são resilientes, isto é, as alterações nas suas configurações mantêm uma espécie de padrão mais amplo, que permanece no tempo, a despeito das perturbações que podem sofrer."

São características que se observam no Sistema Normativo Tributário e que, por essa razão, merecem destaque acaso se pretenda sua alteração. Tal como pontua Junqueira (2015, p. 94-05), todas as reformas tributárias se mostraram infrutíferas por pretenderem ampla alteração no sistema. Para o autor, referidas reformas envolveram grande quantidade de dimensões que, necessariamente, seriam influenciadas por ela, o que prejudica a sua aprovação. $\mathrm{O}$ autor chama de multidimensionalidade referidas questões e ao tratar da situação brasileira pontua algumas das características do sistema que influenciam na multiplicidade das dimensões citadas por ele.

Destaca então que o sistema brasileiro possui um excesso de burocracia, ou seja, os custos de conformidade das leis são altíssimos, tornando o sistema como um todo extremamente burocrático. Ressalta, ainda, a regressividade do sistema tributário brasileiro, uma vez que alta tributação indireta no Brasil, propiciando o aumento da desigualdade social. Pontua ainda a tributação elevada em setores fundamentais à sociedade, como as indústrias farmacêuticas e alimentícias. E, por fim, destaca a desoneração dos setores errados, com a concessão de benefícios não atrelados ao necessário desenvolvimento econômico (JUNQUEIRA, 2015, p. 95).

Considerando o panorama da tributação no país, o autor traz as questões que, para ele, justificam o fracasso das reformas tributárias que se pretendia implementar. Trata, então, das dificuldades políticas decorrentes não apenas das divergências partidárias, mas do poder de veto dos governadores na aprovação das mudanças. Para o autor isso influencia, pois um dos pontos centrais da reforma tributária consubstancia-se no Imposto Sobre a Circulação de Mercadorias e Serviços - ICMS. Tributo de competência dos Estados e do Distrito Federal, é responsável pela maior parte de sustento dos Estados. Contudo, consegue reunir todos os pontos de atenção da tributação no Brasil, pois incide sobre o consumo, de modo a corroborar com a regressividade da tributação e não com a progressividade. Por ser de competência dos Estados, exige um custo de conformação altíssimo, pois qualquer empresa de escala nacional precisa compreender as leis e regulamentos de todos os Estados. E gera uma questão política delicada, pois como nos demonstra Junqueira (2015, p. 100-102), torna-se quase que impossível modificar a forma de tributação por meio do consenso, já que estão envolvidos diversos agentes, com múltiplos 
interesses, no processo de alteração.

Dessa forma, pontua, que a pretendida reforma deve se dar de forma gradual, tal como ocorreu com a alteração substancial na legislação do Imposto de Renda em 1995 e na legislação do ICMS em 1996 (Lei Kandir). Pretender que se opere de forma mais ampla acaba por envolver grande quantidade de agentes do sistema que resistem à modificação.

Esses aspectos demonstram que a alteração que se pretenda no modelo de tributação instituído na Constituição é altamente complexo e exige análise detida das características que demonstram a resiliência do sistema. A resiliência, via de regra, é uma característica positiva dos sistemas adaptativos complexos, posto que o mantém vivo e com suas principais funcionalidades. Contudo, considerando a constante pauta da reforma do sistema tributário, questiona-se se a referida resiliência do sistema tributário é positiva ou se configura aspecto negativo, já que tem se mostrado verdadeiro empecilho às propostas de alteração do sistema.

Exemplo do que se diz é a inclusão do art. 149-A na Constituição. Referido artigo demonstra a adaptabilidade do sistema e a reação às perturbações que pretendem modificá-lo. Antes da Emenda Constitucional n. 39/2002, os Municípios haviam instituído a chamada taxa de iluminação pública, com vistas a arrecadar pelo serviço público de iluminação. Contudo, referida taxa foi julgada inconstitucional pelo Supremo Tribunal Federal - resultando na súmula vinculante n. 41 - uma vez que o fato gerador não era específico e divisível, nos moldes impostos pelo art. 145, II da CF/88, extirpando do ordenamento jurídico a possibilidade de tributar o serviço público de iluminação.

Contudo, diante da referida inconstitucionalidade (perturbação causada pelo Poder Judiciário), foi proposta e aprovada a EC 30/2002, que inseriu no texto constitucional o art. 149-A, prevendo a possibilidade dos Municípios instituírem a Contribuição de iluminação pública, tributo que, ainda que vinculado à sua finalidade de criação (financiamento da iluminação pública), não depende da prestação de serviço específico e divisível a cada cidadão. O exemplo mencionado é típico da utilização dos mecanismos criados pelo próprio sistema para se adaptar às perturbações mantendo sua finalidade - a arrecadação.

Partindo da situação posta e das propostas de alteração, da forma como elencada por Junqueira (2015) identificamos abaixo algumas características do Sistema Normativo Tributário Brasileiro que o torna altamente resiliente. Importa destacar que a lista abaixo não é e não se pretende taxativa, apenas identificando trabalho inicial do tema.

1. Estrutura com ampla previsão constitucional e difícil modificação. Desde 1988 a base normativa do Sistema Tributário Nacional está amplamente prevista na Constituição. É lá que se identificam as competências tributárias, ou seja, quais tributos cada ente da Federação poderá instituir, as espécies tributárias, os fatos econômicos sobre os quais podem ser instituídos os tributos. Também no texto 
Constitucional constam os limites ao poder de tributar, ou seja, os parâmetros principiológicos da tributação, delimitando sobremaneira a legislação infraconstitucional sobre o tema. Muitas das previsões constantes no Capítulo do Sistema Tributário Nacional envolvem cláusulas prétreas, direitos fundamentais, tornando extremamente dificultada sua alteração senão com a mudança da Constituição.

2. Vasta rede tributária (quantidade de tributos): segundo o IBPT 7 , em 2013, o Brasil possuía 89 tributos ativos no Sistema tributário, entre taxas, contribuições, impostos. A vasta quantidade de espécies tributárias ocasiona uma vastidão ainda maior de normas para instituir e regular mencionados tributos, ao ponto de outra pesquisa do mesmo instituto afirmar que no mesmo ano se todas as normas fosse impressas, teríamos um livro de cerca de 112 milhões de páginas. ${ }^{8}$

3. Grande quantidade de agentes: outra consequência é a enorme quantidade de agentes envolvidos. Uma reforma que se pretenda ampla envolve todos os entes da federação, ou seja, União, Estados, Distrito Federal e Municípios, de modo que a quantidade de dimensões (JUNQUEIRA) envolvidas é tamanha que a alteração macro do sistema fica dificultada.

Evidentemente que a proposta feita aqui não é, e não se pretende, exaustiva, mas permite demonstrar que as características identificadas tendem a dificultar a modificação do sistema, que, sendo um sistema adaptativo complexo, apresenta grande capacidade de resistir às perturbações internas e externas.

Além disso, a compreensão de como o sistema tributário brasileiro constrói sua capacidade de resistir a mudanças e as possíveis formas desenhar estratégias legais que possam efetivamente mudá-lo mostra-se um trabalho profundo e meticuloso, sendo este trabalho apenas o primeiro de muitos passos.

\section{CONCLUSÃO}

Dizer que a sociedade, a economia e os sistemas que os regulam devem ser dinâmicos e estão sujeitos a mudanças, não exige maiores questionamentos. Entretanto, a análise das modificações que se fazem necessárias, bem como o preparo para tanto, tem-se mostrado deficiente frente às necessidades sociais presentes. O Sistema Tributário Brasileiro é um bom exemplo do que se afirma. Desde a sua estruturação enquanto sistema ordenado de normas - ocorrido na Constituição de 1988 - foram ao menos 03 propostas de emendas à Constituição frustradas e a constante pauta da necessária modificação do sistema.

O Direito Tributário é uma das principais formas de intervenção econômica - com rápidos reflexos sociais - além de se configurar como uma das principais formas de concretização de objetivos fundamentais da

\footnotetext{
${ }^{7}$ Estudo publicado pelo Instituto Brasileiro de Planejamento Tributário: http://www.ibpt.com.br/noticia/278/Confira-a-relacaodos-tributos-cobrados-no-Brasil

${ }^{8}$ Estudo publicado pelo Instituto Brasileiro de Planejamento Tributário: http://www.ibpt.com.br/noticia/1266/Normastributarias-em-vigor-equivalem-a-livro-de-112-milhoes-de-paginas
} 
República (CF, art. $\left.3^{\circ}\right)$.

Contudo, como demonstrado neste trabalho, o estudo do sistema social enquanto um sistema certo, previsível (característico do paradigma epistemológico newton-cartesiano) parece não resolver os problemas postos pela realidade social. Nesse sentido, como defendido neste trabalho, a complexidade oferece uma nova forma de visualizar esta questão, da forma como propõe Ruhl (2008), Folloni (2013, 2016).

O Direito, como uma tecnologia social (BEINHOCKER, 2006, p. 261), é uma das ferramentas fundamentais de regulação social e econômica. Compreender o próprio sistema jurídico como um sistema complexo, caracterizando os fatores de sua resiliência é o primeiro passo para o desenvolvimento de uma compreensão mais abrangente das razões que levam a extrema dificuldade em realizar mudanças em alguns setores e da incômoda fluidez em outros.

O ferramental emprestado das ciências da complexidade podo ser o primeiro passo para a formulação de uma melhor forma de estruturarmos e pensarmos em como criar leis que incentivem ou previnam as mudanças aferidas pelos limites e características dadas pela resiliência do sistema jurídico e dos sistemas que ele regula. Nesse sentido, procurou-se neste trabalho estudar a resiliência do Sistema tributário Brasileiro, com vistas a identificar fatores que precisam ser atingidos para que seja possível a sua modificação.

Tomou-se o conceito de resiliência ecológica de Holling (1973) como conceito chave para o trabalho posto, considerando-se resiliência como a capacidade de manter as funções, estruturas e identidade fundamentais do sistema adaptativo complexo à medida que as perturbações o acometem.

Partindo desse pressuposto, identificou-se (num primeiro momento) três fatores principais do Sistema Tributário Nacional que caracterizam a sua resiliência, são eles: (i) estrutura com ampla previsão constitucional e difícil modificação; (ii) vasta rede tributária (quantidade de tributos) e (iii) grande quantidade de agentes.

Esperamos, a partir dos elementos delineados neste trabalho, chamar a atenção para uma nova forma de estudar e compreender os fenômenos de mudança do sistema jurídico, especialmente do sistema tributário brasileiro, e a necessidade de uma abordagem multidisciplinar que possa trazer novas possibilidades de atuação planejada em uma seara tão fundamental e delicada para a concretização dos objetivos fundamentais da República brasileira.

\section{RESILIENCE'S ASPECTS OF BRAZILIAN TAX SYSTEM}

\section{Abstract}

Overcoming epistemological reductionism of modern rationality and emergence of complexity has raised new possibilities for both natural sciences and social science - today no longer segregated from the way proposed in modernity. Thus, various phenomena could be analyze from a new perspective. This possibility has reached, even 
if late, the applied social sciences, allowing several of its phenomena could be recognize as complex systems and studied with tools provided by hard sciences in their study. This paper analyzes resilience, as one of the characteristics of Complex Adaptive Systems that can be attributed to legal system, seen as a complex system, with a focus specifically allocated to tax legal system. The aim is identify the main definitions and characteristics of resilience in specialized literature. From then applies these concepts to Brazilian Tax System to seek a correlation of these characteristics with those found in tax system. A system designed not only from the Constitution of 1988, but also, since the enactment of Constitutional Amendment 18/65, under force of the Constitution of 1946. Due this, was identified some of main features of the system, once the identification of these characteristics could allow qualified discussion of proposed amendments to the National Tax System.

Keywords: Resilience, Complexity, Tax System, Taxation, Complex Adaptive Systems.

\section{REFERENCIAS}

ÁVILA, Humberto. Segurança jurídica: entre permanência, mudança e realização no Direito Tributário. 2. ed. São Paulo: Malheiros, 2012.

BARROSO, Luís Roberto. Neoconstitucionalismo e constitucionalização do direito: o triunfo tardio do direito constitucional no Brasil. Revista Eletrônica da Reforma do Estado. no. 09. 2007. Disponível em: http://www.direitodoestado.com.br/artigo/luisroberto-barroso/neoconstitucionalismo-e-constitucionalizacaodo-direitoo-triunfotardio-do-direito-constitucional-no-brasil. Acesso em 27 de jul. de 2014.

BEINHOCKER, Eric D. The origins of wealth. Boston: Harvard Business School Press, 2006.

BOBBIO, Norberto. Da estrutura à função: novos estudos de teoria do direito. BarueriSP: Manole, 2007.

BYRNE, David. Complex theory and the social sciences: an introduction. New York: Routledge, 1998.

CALIENDO, Paulo. Direito tributário e análise econômica do direito: uma visão crítica. Rio de Janeiro: Elsevier, 2009.

CASTI, John. X-Events: Complexity Overload and the Collapse of Everything. Harper Collins: New York, 2012.

DIB, Natália Brasil; FOLLONI, André Parmo. A tributação à luz da teoria do bem jurídico: análise de suas dimensões e funções junto ao desenvolvimento. 2015. 131 p. Dissertação (Mestrado) - Pontifícia Universidade Católica do Paraná, Curitiba, 2015 Disponível em: $<$ http://www.biblioteca.pucpr.br/pergamum/biblioteca/img.php?arquivo=/00005a/00005a6f.pdf > Acesso em 12 jan 2017.

FOLLONI, André. Ciência do direito tributário no Brasil: crítica e perspectivas a partir de José Souto Maior Borges. São Paulo: Saraiva, 2013.

A complexidade ideológica, jurídica e política do desenvolvimento sustentável e a necessidade de compreensão interdisciplinar do problema. Revista Mestrado em Direito (Unifieo, impresso), v. 41, p. 63-91, 2014.

Introdução à teoria da complexidade. 1. ed. Curitiba: Juruá, 2016. 
HOOKER, Cliff (Org.). Handbook of the philosophy of science volume 10: philosophy of complex systems. Oxford: Elsevier, 2011.

GRAU, Eros Roberto. A ordem econômica na Constituição de 1988. 13. ed., São Paulo: Malheiros, 2008.

GRIMM, V.; WISSEL. C. Babel, or the ecological stability discussions: an inventory and analysis of terminology and a guide for avoiding confusion. Oecologia. Springer-Verlag: Berlin Heidelberg, Volume 109, Issue 3, p $323-$ 334. HOOKER, Cliff (Org.). Handbook of the Philosophy of Science volume 10: Philosophy of Complex Systems. Oxford: Elsevier, 2011.

GRIMM, Volker; CALABRESE, Justin M. In.: DEFFUANT, Guillaume; GILBERT, Nigel (Org.). Viability and resilience of complex systems: concepts, methods and case studies from ecology and society. New York: SPRINGER, 2011.

HOLLING, C.S.; GUNDERSON, L. H. Resilience and adaptive cycles. In.: Panarchy: Understanding transformations in human and natural system, Island Press: Washington, 2002.

HUMBY, Tracy Lynn. Law and Resilience: Mapping the Literature. In.: Seattle Journal of Environmental Law. Volume 4, Issue 1 1, 2014.2 Disponível em: <http://digitalcommons.law.seattleu.edu/cgi/viewcontent.cgiarticle=1032\&contex =sjel $>$ Acesso em 12 jan 2017.

INSTITUTO BRASILEIRO DE PLANEJAMENTO TRIBUTÁRIO - IBPT. Confira a relação dos tributos cobrados no Brasil, 2013. Disponível em: < http://www.ibpt.com.br/noticia/278/Confira-a-relacao-dostributos-cobrados-no-Brasil> Acesso em 12 jan 2017.

Normas tributárias em vigor equivalem a livro de 112 milhões de páginas. 2013. Disponível em < http://www.ibpt.com.br/noticia/1266/Normas-tributarias-em-vigor-equivalem-a-livro-de-112-milhoes-depaginas > Acesso em 12 jan 2017.

JUNQUEIRA, Murilo de Oliveira. O nó da reforma tributária no Brasil. In.: Revista Brasileira de Ciência Sociais, v. 30, n. 89, outubro de 2015, p. 93-99. Disponível em: < http://www.scielo.br/pdf/rbcsoc/v30n89/0102-6909rbcsoc-30-89-0093.pdf> Acesso em: 12 jan. 2017.

KAUFFMAN, Stuart A. Reinventing the sacred: a new view of science, reason, and religion. New York: Basic Books, 2010.

KELSEN, Hans. Introduction to the problems of legal theory: a translation of the first edition of the reine rechtslehre or pure theory of law. New York: Oxford Press, 1992.

MAYNTZ, Renate. Resilient financial systems: methodological and theoretical challenges of post-crisis reform In: MAURER, Andrea (Org.). New Perspectives on Resilience in Socio- Economic Spheres. Springer: Wiesbaden, 2016.

MAURER, Andrea. Introduction: new perspectives on resilience in socio-economic spheres in MAURER, Andrea (Org.). New Perspectives on Resilience in Socio- Economic Spheres. Springer: Wiesbaden, 2016.

In search of the golden factor: conceptualizing resilience in the framework of new economic sociology by focusing 'Loyalty' In.: MAURER, Andrea (Org.). New Perspectives on Resilience in Socio- Economic Spheres. Springer: Wiesbaden, 2016. 
MARINS, James. Aspectos críticos sobre a segurança jurídica em matéria Tributária. In.: Ives Gandra da Silva Martins e Humberto Àvilla. (Org.). Segurança Jurídica em Matéria Tributária. 1ed.Porto Alegre: Editora Magister, 2016, v. 1, p. 03-1001.

MIRANDA, Jorge. Teoria do estado e da constituição. Rio de Janeiro: Forense, 2002

MITCHELL, Melanie. Complexity: a guided tour. New York: Oxford Press, 2009.

NABAIS, José Casalta. O dever fundamental de pagar impostos. Coimbra: Almedina, 1998.

PAYING TAXES 2016. PWC, London, n. 10, 2016. Disponível em: <https://www.pwc.com/gx/en/payingtaxes-2016/paying-taxes-2016.pdf>. Acesso em 22 set. 2016.

PRIGOGINE, Ilya; STENGERS, Isabelle. La nueva alianza: metamorfosis de la ciencia. Madrid: Alianza Editorial, 1990.

PRIGOGINE, Ilya; STENGERS, Isabelle. Order out of chaos: man's new dialogue with nature. Bantam Books: New Yok, 1984.

QUEIROZ, Marisse Costa de. O direito como sistema autopoiético: contribuições para a sociologia jurídica. In.: Revista Seqüência, n. 46, p. 77-91, jul. de 2003. Disponível em: < https://periodicos.ufsc.br/index.php/sequencia/article/view/15292> Acesso em: 26 jun. 2015

RIBEIRO, Ricardo Lodi. Piketty e a reforma tributária igualitária no Brasil. In.: RFPTD, v.3, n.3, 2015. Disponível em: < http://www.e-publicacoes.uerj.br/index.php/rfptd/article/view/15587> Acesso em 12 jan 2017.

RUHL, J.B. Law's Complexity - A primer. Georgia State University Law Review Symposium Issue, Forthcoming, FSU College of Law, Public Law Research Paper No. 313. 2008. Disponível em: <https://papers.ssrn.com/sol3/papers.cfm?abstract_id=1153514> Acesso em: 12 jan 2017.

General design principles for resilience and adaptive capacity in legal systems: applications to climate change adaptation law. North Carolina Law Review, 2011. FSU College of Law, Public Law Research Paper No. 464. Disponível em: < https://papers.ssrn.com/sol3/papers.cfm?abstract_id=1694187> Acesso em: 12 jan 2017. Complexity theory as a paradigm for the dynamical law-and-society system: a wake-up call for legal

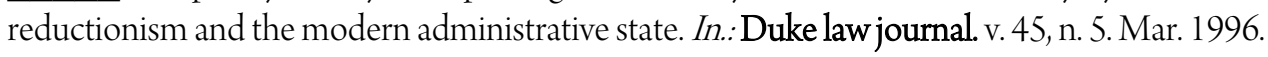

SCHOUERI, Luís Eduardo. Normas tributárias indutoras e intervenção econômica. Rio de Janeiro: Forense, 2005.UNGAR, Michael (Org.). The Social Ecology of Resilience. Springer: New York, 2012.

SOUZA, Rubens Gomes de. A missão do jurista tributário. IN.: Revista de Direito Administrativo, v. 78, 1964. Disponível em: < http://bibliotecadigital.fgv.br/ojs/index.php/rda/article/view/26724> Acesso em 12 jan 2017.

TEUBNER, Gunther. O direito como sistema autopoiético. Lisboa: Fundação Calouste Gulbenkian, 1993.

TORRES, Ricardo Lobo. Curso de direito financeiro e tributário. 9. Ed. Rio de Janeiro: Renovar, 2002.

WALKER B., HOLLING C.S., CARPENTER S.R, KINZIG, A. Resilience, adaptability and transformability in social-ecological systems. Ecol Soc 9(2):5. 2004. Disponível em: <www.ecologyandsociety.org/vol9/iss2/art5> Acesso em 12 jan 2017. 
Trabalho enviado em 15 de janeiro de 2017. Aceito em 16 de abril de 2017. 